\title{
To Rethink the Preparation of the Expatriates (1)
}

\author{
Jocelyne Robert \\ Professor \\ HEC-Management School of the University of Liege \\ Email Address \\ Jocelyne.robert@ulg.ac.be \\ Adeline Goemans \\ Master in Human Resources Management \\ Phacobel \\ Email Adress \\ Adeline.goemans@gmail.com
}

\begin{abstract}
Not every expatriation results in success. Some expatriates come back to their home country earlier than expected or do not achieve the targeted objectives. We here aim at highlighting different types of difficulties but also at identifying factors that may reduce the latter. This study, realized in 2011, is the result of an exploratory research based among 45 Belgian and French expatriates on mission in India, China and Europe. We will underline the necessity for a contingent approach of the preparation. The preparation differs from one expatriation to one other and the role of the Human Resource in the host Countries is as important as the role of the Human Resource in the Head Quarter. The preparation differs from one expatriation to one other. We purpose also to define a first expatriation as a training time for the following expatriations, especially if the following expatriation is in a context culturally different or if work conditions are different of these from the home countries. This first expatriation will have to be longer to impact the next expatriation and to enable the expatriate to prepare for cultural differences, acculturation and change in different context. After, the beginning of each expatriation will be training at the particular condition of expatriation but will be more eased and accelerated, as the expatriate already is trained in adapting and cultural differences but as to learn about the particularities of this expatriation.
\end{abstract}

(1) Thank you to Alicia Delagrange and Marie Moreau for their collaboration at the first step of this research. 
The globalization of economic activities has largely contributed to the increasing importance of the expatriation. Companies need now to send their executives abroad for a certain period of time. However, not every expatriation results in success. Some expatriates come back to their home country earlier than expected or do not achieve the targeted objectives. More generally, the real impediments to realizing the mission are observed to be the difficulties encountered during the period of the expatriation. We here aim at highlighting different types of difficulties but also at identifying factors that may reduce the latter. This study is the result of an exploratory research based among 45 Belgian and French expatriates on mission in India, China and Europe.

\section{Definition}

According to Romero, an expatriate would be « an highly qualified worker with unique skills, who is sent in an other department of the same company located in an other country, generally on a temporary basis". (we are translating ) (Romero, 2002: 73). Those who are expatriates on their own initiatives are to be distinguished from those sent by the organization for which they are working. Besides, a difference remains between long-term and short-term placement. A long-term placement, which usually lasts from one to five years, is called expatriation. Such a placement allows the accomplishment of a strategic mission, a knowledge transfer, a control and professional development. A short-term placement, in turn, concern the international commuters or frequent flyers. This international mobility last from 1 to 12 months and targets technical missions allowing both knowledge and managerial development (Waxin and Barmeyer, 2008 : 111-112).

\section{Failures and difficulties encountered}

With more than $50 \%$ of expatriates failing to respect the required tasks during their mission, it can be concluded that very often expatiation result in a failure (Romero, 2002 : 74, Copland and Griggs, 1985 : 74). There are 3 ways to observe a failure: the lack of performance, the untimely 
return or leaving the company a little time after the end of expatriation. Yet, it is important not to forget that, in some cases, an earlier return can be considered as a success (Palmer and Varner, $2005: 5$ ). Thus, other factors are to be taken into account when considering the expatriation failures. For example, such factors are the effectiveness during the stay, the acquired knowledge of the expatriate, the way the company will take benefit of these competencies gained by their employees and, finally, the time the expatriate stays within the company after their return (Varner and Palmer, 2005 : 6).

The failures can be explained by numerous factors (Scullion and Colings, $2006: 60-61$ ) like the duration of the mission, the focus on technical skills or the lack of preparation for international missions. The difficulties encountered are due to both private and professional factors. According to different authors, the theory of the adaptation explains these difficulties by 3 types of variables are linked to; individual, organizational and contextual variables.

The individual variables are those related to the personality of the expatriate. The personal and intercultural qualities of individuals are factors that may explain success or fail during expatriation (Bonache and al, 2007). The expatriates can also have organizational difficulties (Waxin, 2000). The organizational variables concern the clear definition of the role and the possibility of autonomy, objective differences between roles, organizational social support, the newness of the organizational culture and intercultural preparation. Misunderstanding in communication may happen between the company and the division about the role of the expatriate that is therefore not clearly identified. When the expatriate does not know what to do, the latter feels stressed and has difficulties in adaptation and in achieving the targeted mission. In the same way, the differences in organizational cultures can explain the problems encountered at work. The expatriate can also feel a lack of technical competence facing new challenges or unable to assume responsibilities (Tung, 1981: 76). As for Cerdin and Le Pargneux (2008). The uncertainties concerning the conditions of coming back also add an important stress and affect the adaptation to the new environment. Sometimes, some authors assume that short-term placement is 
even more complicated than long-term ones (Tung,, $1987: 117-118$ ).

Finally, last variables concern the context and the familial situation and are related to the situation of each expatriate. The family situation, the support from the partner, time passed abroad, cultural distance, home country and host country together with economic and political context influence expatriation. The familial situation plays an important role (Mérignac and Roger, 2005). Besides the difficulties related to children, the question of double career appears. The partner faces an important choice: keep working in the host country or postpone their career (Guerrero and al, 2004). Concerning the children, they need to go to school, to receive health care services, to receive support before and after expatriation. The home country also determines the importance of changes in daily life to which expatriates and/or their families should get used to. The cultural distance determines the difficulties of expatriation and, in the same way, daily difficulties that may arise from a cultural chock (Waxin, 2000).

These different problems can together bring obstacles to the success of the expatriation on both private and professional level, that's why it is important to analyze the existing means.

\section{Preparation, Training and Follow-Up of the Expatriation:}

\section{Solutions to problems encountered?}

In order to overcome such difficulties, 3 types of support are mentioned in the literature. The expatriates need to be prepared to their mission, to be coached by their mentor and to find support in the host country. We will distinguish, among measures to put into place, the preparation and pre departure training, including the visit of the host country, post arrival training that may include a follow-up once in the host country. Finally, we will discuss sequential training which includes the two latter (Selmer, 2002). Here, we will not take into account the preparation at arrival.

After having presented the training and the supports of expatriates, we will discuss the reasons 
why some enterprises are reluctant to organize them. We will therefore understand the limits and highlight the need of a contingent approach including specifics of previous situations.

\section{The utility of the Training}

The companies that succeed prepare their expatriates by providing them with detailed information on relocation, tax and other indications rather than on the inside of the mission and wage-related compensations. Short training also include discussing cultures, traditions and other information on the country. These companies prepare, for the expatriate and their family, a trip in the host country such that they visit the company and the place where they will live. After this visit, they have an idea about the place they will be living in (Oddou, $1991:$ p. 305). The preparation, for many, is the key for success during expatriation (Baliga and Baker, 1985 : 34). Other assume that «employees that are well qualified and prepared work better and more efficiently, with less mistakes, require less supervision, are more enthusiastic and are less likely to leave» McCaughey and Bruning, $2005: 25)$. McCaughey and Bruning (2005 : 26) point the importance of the family in the preparation of an expatriation out.

Training may also seem to be a solution of preparation when the company faces difficulties in finding the right candidate that meets the selection criteria (Gertsen, 1990). Doing so, the company creates their own candidate and offers them the specifically needed training for the mission.

\section{Pre departure support}

This support is an administrative support implemented by the company but also contains briefings and travels.

Administrative support: This helps reducing stress and overcoming problems. The expatriates can, 
therefore, focus easily on their professional activities. This help concern the research of an accommodation or a school, information related to the daily life, a job for the partner, insurance, more generally, administrative requirements (Aycan, 1997: 445; Waxin and Barmeyer, 2008 : 131). Some companies can also ask outsource this service thanks to specialized firms.

Informal transactions can also be organized between the expatriate, their family and employees coming back from the host country after their expatriation (Vance and Paik, $2010: 251$ ). Yet, Fitzgerald-Turner (1997) and Black (1988) highlighted that expatriates receive almost no support before their departure but some advices on taxes and accommodation (Vögel and Van Vuuren, 2008 : .34). According to Briscoe, Schuler and Claus (2009: 222), it is important that the expatriate and their partner know about new responsibilities, wage-related compensations, taxes, rules, security and relocation possibilities. Waxin and Barmeyer (2008) suggest few days of holiday or schedule arrangement such that the expatriate can get the sufficient information about the social events in the country.

\section{Briefings}

The briefings allow the expatriate to have an idea about the following: geography, climate, demography, history, government, life conditions, etc. These cheap briefings are useful information but not enough to impact the behaviour of managers (Perkins and Shortland, 2006 : 110; Selmer, Torbiörn and de Leon, 1998, p. 835 ; Selmer, 2002 : .39).

\section{The visits of the host country}

These visits are organized before the departure, during or after the procedure of selection, in order to experience during one week on average the life abroad. By doing that, the expatriate can have a better knowledge about the culture of the company and choose a better accommodation and school for their children if needed or search for a job for their partner (Perkins and Shortland, 2006, p. 111 ; Waxin and Barmeyer, 2008, p. 126). 


\section{Different Types of Training}

Among pre departure training, language and cultural training can be mentioned.

The language training (Perkins and Shortland : 112) are particularly important because in order to be performing in an international context, the knowledge of the local language is essential (Harrisson, 1994, p. 2). Even if some companies' managers think that the knowledge of English is enough in business world, some do not agree. According to them, the knowledge of English is not enough for being successful in an international context (Oddou, 1991, p. 305).

The intercultural training bring information and allow a beforehand preparation to the host country and to its traditions, differences and particularities. This can be considered as a way, in a practical context, to teach adaptation,to manage staff and to build teams and negotiate. Moreover, learning about the host country and understanding its culture is a way to overcome cultural choc. (Perkins and Shortland, 2006 : 113-114 ; Selmer, 2002 : 38 ; Waxin and Barmeyer, 2008, p. 126).

The post-arrival training compensate short pre-departure training. According to some authors, post-arrival training are more efficient for the expatriate (Selmer, 2002: 40). They are on the job-training allowing the expatriate to learn by doing. Short-term performance is therefore achieved. These training include language and cultural training (Sekiou and al., 2001, p. 338).

The personal coach is important during the preparation as well as during the expatriation as such. This is an alternative for the traditional pre-departure training. An external consultant is there to help the expatriate with their knowledge about the social and economic context of the country. This consultant can intervene as soon as expatriates meet difficulties. Thanks to the technology, coaching can be achieved from abroad but it is preferable that the consultant is present in the host country (Selmer, 2002).

The mentoring is characterized by the intervention of a predecessor owning sufficient information. Mentoring may be expensive therefore may not be considered by companies (Selmer, 2002). 
Besides the important role of human resources in implementing a favorable business culture to the mission of the expatriate, can be neglected (Schaaper, Amann, Jaussaud, Nakamura, Mizoguchi, 2013).

The sequential training combines pre-departure and post-arrival training. It is above all focused in multicultural training. Three conditions characterize the sequential training. First, social environment should be really different. Then, transfer to the host country should be sudden. Finally, the stay should be such that the expatriate has time to adopt and integrate. So, the learning is done step by step allowing each of them to be fully understood ((Selmer et al.,,1998: 835 ; Selmer, 2002 : 41). Even if some studies have shown the importance of training (Romero, 2002 : 75), many do not fully consider such training and expatriates are often prepared superficially (Waxin et Barmeyer, 2008 : 129-130). In 1985, Schwind notes that « the majority of companies involved in international trade do not provide training and preparations for international mobility » (Mendenhall and Oddou, 1986 : 77). Oddou confirms this affirmation via a study including interviews of 165 expatriates, of which $65 \%$ did not receive training. This study reveals that only $26 \%$ of expatriates with a training declare that training helped (Oddou (1991: 302). Despite discussions favoring training and preparation, this study reveals doubts concerning their efficiency on the achievement of the mission.. The financial and time costs are also barriers. The cost of a training is a common reason why companies are reluctant to propose some, especially in case of short stay (Selmer, 2002: 38 ; Gertsen, 1990: 351 Tung, 1981: 76). In addition, post-arrival training can disturb dynamic managers and drive them away from their main objective: the mission (Selmer, 2002 :38). Finally, according to Black and Mendenhall (Oddou, $1991: .304)$, it is important to understand the content and the method of training with the type of experience that the expatriate will have. Tung (1981) reveals the same results through a survey that confirms the importance of a contingent approach of the training and preparation methods. 


\section{Contingent Perspective}

According to Tung (1981), training are efficient only if they take into account the situation of expatriates and if they adopt a contingent procedure. For example, during expatriation in China, it is important to prepare managers for a new work and life environment (Selmer, 2002). Managers need strong flexibility and to adopt managerial practices to the host country culture.

Training should therefore focus on such differences in practices to help the expatriate (Tung,1998).

According to Mendenhall and Oddou (1986, p. 78), the training should take into account several parameters such as the stay, the home and host culture, the civil status, children, the position of the expatriates in their company, the type of interaction with locals and the probability that the manager needs cultural skills later in their career. Panaccio and Waxin (2004) confirm that the training should take into account the cultural distance, the nature of expatriation, the sector and the contract. The training can also be proposed in order to give incentives to the family that, in turn, will influence positively the expatriate. Unfortunately, few companies propose a training program designed to the family (Gertsen, 1990). Tung (1981) assumes that the training should be adopted to the expatriation. It is, indeed, important to match the content and the method (Oddou, $1991: 304)$.

However, one criteria of selection is more important than anyone else; the previous experience in the same host country. The study of Church (1982), states that the previous international experience should be such that the expatriate can be totally prepared to their mission. This previous experience may have a positive influence (Selmer, 2002). When the previous experience has been a success, training can be reduced and thereby, costs. Extra roles can be attributed to the expatriates, consultant or personal coach. However, an experience in a similar country is not necessarily efficient. 


\section{Methodology}

During our study, realized in 2011, a qualitative approach has been used and we have given priority to a comprehensive analysis highlighting the means and reasons of the situation (Quivy and Van Campenhoudt, 2011). Then, the experience of expatriates has helped in understanding the difficulties encountered and the means proposed (Miles and Huberman, 2003 ; Yin R.K., 1994).

In order to build our sample, several ways have been used : Alumni, AWEX, websites. Previous students have been asked about their expatriation. Also, thanks to organizations, we could get in touch with expatriates, namely AWEX. Finally, some of them have been contacted thanks to websites. In order to obtain a "snowball effect", we have asked them to get in touch with other expatriates.

The 45 people have first been contacted by post. Once they agreed, interview charts have been sent to them before a Skype or phone conversation was agreed. Only 2 people could be contacted face to face. These interviews lasted between 30 minutes and 1 hour. As for our qualitative approach, a recapitulate table has been realized where an analysis has been conducted by theme (Thiétart and coll., 2007). We highlighted sentences, words and expressions in order to put into evidence similitude and differences.

The majority of 45 executives are Belgian. Some work for private companies (28), and other for public organizations (14), 2 work as independent abroad and one of them is retired and works in an high school. 35 interviewees had previous expatriation experience. These expatriation experiences concern all parts of the world and, some of the expatriates, where living abroad since a long time. Therefore only 10 of them never had experienced expatriation before. 35 men and 10 women have been met. 28 are married, 6 are in a relationship and 10 are single. The majority has been sent to Asia, 15 to China and 10 to India, 13 to Europe, 4 to US and 1 to Australia. We then could make a link between the difficulties encountered and the strong cultural difference since the major party of the expatriation concerned Asia. Some experienced 4 years of expatriation some 
longer. Especially, economic and commercial representatives are involved in expatriation of unspecified duration.

\section{Presentation of results}

\section{The difficulties encountered}

First, note that over 45 expatriates, 8 seem not to meet difficulties. An expatriate in Austria indicates : « My expatriation concerning Europe, differences are not that important. I did not have any difficulties. ». Another person considers that such a challenge is part of their job : «We normally are prepared to face unpredictable situations and this is the challenging side of our job. ». However, he indicates that some risks are not to be neglected: «Revolutions and other corporate risks are to be put aside, of course. ». These expatriates think that the difficulties to be encountered are also to be solved by them but some risks (revolutions...), are somehow inevitable. Note that the above mentioned expatriates had already 31 years of experience abroad.

Very few expatriates have nostalgia about their home country, Belgium. They sometimes have adaptation difficulties in a different environment. This adaptation difficulty can be linked to a difficult moment of expatriation or to a destination culturally, politically, socially and/or economically very different. According to an expatriate who particularly had a very difficult expatriation period «Once we understand life abroad, we can get used to it.». The problem comes from the inability to understand such differences. "The signification of the terms is not the same: tomorrow does not mean tomorrow. |... $\mid$ Asking for a task is asking several times (It is almost an harassment. ».The interviewee has several problems in their daily life: communication problems, lack of supermarkets, consumption goods, and European products, «Everything is difficult, boring. Everything is different: lifestyle, leisure, food, music.» With time, this person got used to those differences «I even had friends». However, other expatriates, facing same problems, are satisfied. "With locals, time is needed. They are cool. Nothing is never too serious 
but we get used to that. India cannot be explained. People are smiling, welcoming ». An other expatriate talks about the same destination with enthusiasm. She particularly appreciates India's « exuberance, welcome, tolerance, philosophy, daily life, myths, diversity, food specialties ». As we can see, different people have different views about a same place. As another expatriate says «You like or you don't. ». The time needed for adaptation depends on the destination: «Cultural choc has lasted more than in other countries ». It can also depend on the expatriate's experience abroad, on its local encounters. The expatriates can feel lack of preparation or of relational skills. "The methods are not the same. They do business totally differently. The approach is different but also human relations."

Another difficulty is the problem of communication with the head company. This deficient communication concerning the head company can result in lack of clearness or information that locals have regarding the mission of the expatriate or lack of head company's comprehension, lack of recognition and finally, uncertainty of post-arrival conditions. Many complain about clearness issues regarding their mission. "Instructions could have been clearer, and ambitions more precise ». Some expatriate regret also local people's lack of information about the objectives of the expatriate's mission. Subsidiaries employees feel those mission as intrusions and only see the supervision, control, expertise, restructuring that bring the presence of those head office representatives. This can explain the reluctance of local people and may disturb the expatriate. Moreover, an expatriate adds «directly integrating the local department, to get along with local management and not to hesitate to take distance from the indicated tasks. The head company owns a superficial view of the work to be done abroad. ». This lack of knowledge about the expatriate's upcoming situation also constitutes a restraint. «People in the head company do not always experienced expatriation or have a misleading understanding of the situation ». An expatriate explains «Many problems come from the central administration in Belgium. I had lots of problems with colleagues whose opinion was that I was having summer holidays on the beach in front of the sea....». Besides, the expatriates may feel underestimated by the head company. 
They have problems communicating with their colleagues who do not have sufficient knowledge about their situation and who idealize their working conditions.

The family, in turn, can also be source of problem, especially for their children who should go to high school and may have health-issues. Even if many go abroad with their families, they do not mention them as a source of problem. One, however, says : " The more there are people, the more it is difficult». When travelling with the family, there are more responsibilities. «The principal problem is that I travel with my family».

Another difficulty is the one related to the language. This difficulty is mentioned by those who are expatriates in China since the basic knowledge is far from being sufficient and that, despite a pre-departure training. There are cultural, philosophical differences rendering communication more difficult. This situation seems to be true in China while in India, daily life seems to be the most important source of problems.

Some problems such as health issues of the family occurring in the host country are almost impossible to prevent. This is also the case when political issue occur, as revolutions or even wars.. Even if such preparation may be impossible, the expatriate and his family should be fully aware of those possibilities, as anticipating is already part of preparation.

\section{Contingent Approach}

Difficulties are those related to departures, experience of expatriation or the conditions in the host country. For example, expatriates who assume their experience as being personal do not mention language or cultural difficulties but problems with parent company. The previous experience, as being said, is also there to help improving conditions and to allow expatriates to reduce difficulties.

According to the country and the experience, the understanding of the culture "the revelation" is more or less quick. With this revelation being occurred, difficulties can be managed more easily. If they already had such a revelation before, then this is even easier. However, the more there are cultural differences the more adaptation is difficult. 


\section{Search for Solutions}

\section{Language and Technical Training}

First, focus is given to these two training that seem to be the most challenging items during the mission. The expatriates essentially received language and technical training : "I have received language training, nothing automatic ». «I had a language training and technical updates». «I had basic Chinese lessons » «I had an introduction Chinese course ». However, such training are not always organized and are not always sufficient : «There should have been more classes». « Language training was useful, sad that the family could not join ».

Some received information about the tax system and logistic issues (accommodation, installation): «Preparation to the administrative part and the health care organization» «Administrative preparation; visa ... and for moving».

\section{Briefing}

Some received an information day about intercultural differences. That is the most frequently mentioned. «I received information about differences between Chinese and French culture. This helps but not always I mostly learned from my own mistakes that I still make». Another also received a likely training and assumes having learned from previous experiences. «I received half a day training. This helped me. This was about specific aspects of India: cultural differences between France and India, infrastructures, traditions, cast system, etc... But this training was quite disorganized, not long enough and did not really help me. Certainly, my experiences in Korea, in Canada or Brazil help me to integrate the country. I was not anxious or stressed...my partner had more to tell since she had never been so far for such a long period of time ». Another had no information at all: «No training ...This was not mandatory. The best training is the on-the-field training ». 


\section{Mentoring and Tutorial}

Three expatriates enjoyed help of a mentor. One among them precise: «The preparation is different regarding the country where we are going. For me, there was a mentor in the host country for the first steps in the country and in the company [... ]. This could have been better if we had two mentors: one in Belgium to keep in touch with the head company and avoid feeling of isolation, forgotten by the company and one in host country. Finally, now, we have intranet $\gg$. The expatriate mentioned the importance of the two tutors: one in the home country and the other in the host country. This double mentoring exists but not everywhere. In our sample, only one expatriate had double mentoring.

The impact that allows mentoring and different types of personalized follow-up, remains uncertain : some see some support, some practical help, some a source of advice, some, finally, a way of building network... For the expatriate in China, the mentoring was linked to the learning of a language «I had 30 hours of Chinese when I first arrived, they waited my arrival to start the training. Some previous teachers help new students, but quite informal, not considered as a support program. It is more about willingness ».

Very few of them mention mentoring. They mention the high price of such training. Expatriates, yet, experience such follow-ups informally by asking for help from previous expatriates or superiors. One of them explains «I was followed by a superior. As soon as I had a problem, I could ask for help. They were always available to help me in any context... at work...in life ». Another would have appreciated to be able to have a mentor during the first year of their stay. Three of them mention the informal tutorial they had by having previous expatriates helping them during the first week of arrival in the host country : «I am in touch with my predecessor. He gives me advice about the country but also for the job. We, however, do not have official «mentoring». This helps me a lot». This expatriate and his wife received training before and after their leave. The cultural training included case studies, debates and presentations: «It was 
rewarding and interesting ». On the field, they rather received information: «At the moment of the arrival, there has been a presentation explaining the difference between India and France realized by a French coming originally from India. This is useful ». "We had a brief overview of major differences. This took one day, after few days of my arrival. Yes, this helped me. They have explained me cultural aspects of India. I was aware about my new coming life 》 Another employee arrives in an 'occidental' country and positively remarks the utility of a training in the host country about the cultural and administrative differences. "The US company proposed technical, administrative and welcome training ».

\section{Internship and Visit}

Some companies organized visit previous to departure. Yet, only 4 expatriates had the opportunity to travel to the host country before their real departure. «We had 3 month internship in the Central Office in order to better understand the country» says one of them. «I had 1 week stay before my real departure » says another one. «I have been twice and stayed 1 week each time before I moved». Some had longer journeys: «I stayed one month in the country before my departure for the administrative procedure», "I have passed one recognition month to meet my predecessor $\gg$.

Companies rarely implement such procedures. Yet, all types of training and follow-ups mentioned above all, even when organized all together, seem not to be sufficient. The technical training does not allow to avoid cultural and adaptation difficulties. In the same way, intercultural training did not always allow to reduce difficulties linked to the daily life and particularly, in a country like India. Language training can seem to be strongly insufficient for expatriates in China, for example. As for the coaching organized by colleagues, it is about the accomplishment of the work and does not guarantee adaptation. 


\section{Discussion}

Our study allowed us to highlight the contingent side of expatriation (Tung, 1981). Each expatriation has its own variables that will determine the needs les in terms of preparation or training and that will influence the apparition of difficulties. Consequently, the situation of the expatriate is analyzed from a personal and professional point of view but also the circumstances and mission of the expatriate. At a personal level, the acquired experience and familial support are two essential components to take into account. At a professional level, circumstances, content of the mission, training and the follow-up are important to be understood in order to find solutions or problems encountered. To this extend, our expatriates confirm the lack of training (Waxin and Barmeyer, 2008 : 129-130). Those who had such training found them helpful but insufficient. According to the interviewed expatriates, it is about adapt preparation, training and follow-up of particular situations. Thus we agree with Tung (1981) or Black and Mendenhall (1991).

The personal situation of the expatriate can therefore be improved by associating the family during the preparation and training (Gertson, 1990, Tung 2003). Indeed, we have observed the importance of the help from the family for adaptation. Integrating the family during the preparation and training procedure may prevent possible upcoming difficulties concerning the family and their adaptation.

The necessary preparation and training will depend on the country and the company. Intercultural, tax, administrative and language training depend therefore on the country in which the expatriate is sent. However, it is also important to determine the context in which the expatriate will work : will their colleagues have an international background, will they be locals or have the same nationality than the expatriate...? Depending on the working environment, both the preparation 
and the training have to be adapted. The expatriate should, for example, be trained in order to work with local people and receive information about that. Our expatriates defend sequential training associating pre-departure training to the post-arrival training (Selmer, 2002), provided that post-arrival training is sufficiently personalized and that it enables problem solving. There is then compensation with insufficient pre-departure training. To this extend, a personal coaching can be interesting in order to organize these post-arrival training.

Moreover, our study could highlight the importance of coaching specific to the place (Tung, 1981) allowing the expatriate to be followed and their adaptation to each environment and to their evolution. Rarely used, coaching seems to be satisfying. However, expatriates regret when there is coaching from far away. Indeed, in the host country, coaching enables personalized follow-up adapted to the situation and to the country. As for the mentoring (Selmer, 2002), this method is rarely used. However, it seems to be used frequently but not officially, by expatriates asking for advice to their predecessors. Along our study, we have seen that expatriates appreciate to be followed both by a coach or mentor in the host country or a mentor in the head company.

Our study also points the uncertain situation of an expatriation, that is not solved neither by training, nor by preparation. Those uncertainties can only be anticipated thanks to preparation or training. Lots of expatriates insist on the uncertain character of the situations and the impossibility to avoid some encountered problems: the preparation and training do not prevent neither erase all the difficulties. That's why the head company should inform the future expatriate about the difficulties that may occur. The past experience is not a guarantee for avoiding future difficulties. However, it is an important reducing factor, by its influence on stress and by the things the expatriates have learned by their mistakes. It also plays a role towards the family that is more used to live abroad. Past experiences surely have a great impact, but, like training and preparation, do not prevent of all difficulties and do not give a specifically training (difference in 
country, mission, personal situation).

One new component appears to be the lack of communication between the head company and expatriates but also between the head company and local employees of subsidiaries. The absence of a definition for the mission is a huge problem. Whatever the country, if the mission and the position are not clearly identified, there is problem. The head company has a role to play. It, also, would be very useful to identify the conditions of arrival and return and the content of the future mission before the ongoing expatriation. The attitude of the colleagues and their judgment is also very important wherever they are located.

Our study highlights the importance to adapt preparation and training of the expatriate to their specific situation (Tung(1981), Oddou(1991), Black and Mendenhall (1990)) but also to rethink expatriation in general. In fact, interviewed expatriates highlighted the importance of time in adaptation procedure such that a «revelation » occurs. Therefore, expatriation should be made longer, when possible, for the expatriate to have sufficient time to adapt and the company to take benefits. The period of expatriation, i.e., should be longer and the same expatriate should be sent to the same place such that the experience is enriching. It is then important to take into account the past of the expatriate before making an expatriation decisions but also in the training of the new candidates, meetings with predecessors is important. Then, a first expatriation as a training time for the following expatriations, especially if the following expatriation is in a context culturally different or if work conditions are different of these from the home countries

\section{Limits}

The size of the sample may be deceiving. However, the latter helped us to determine a tendency. Despite its size, the sample helped us to be aware about necessities and about the need for taking into account the specific situation of the country of destination. The contingent character of 
expatriation has been shown (Tung, 1981). Case studies have therefore been considered as the method of research. These can enable a better comprehension and knowledge of the specific situation. When some difficulties have specifically not been taken into account, such as those related to the return in the home country, our study has been challenged. Finally, when directly asked about difficulties, expatriates search for the existence of difficulties while spontaneously, they would not always feel important to mention them. The search tool (semi-directive meetings) and questions can have an influence on the answer.

\section{Conclusions}

The goal of this study was to understand the difficulties encountered by interviewed executives and how, particularly for companies, to prevent them. The method used is qualitative; the answers brought other questions and therefore the need for more information. Our study shows the importance of contingent approach. Measures have to be taken to enrich expatriation. The type and length of training, namely language training, have a different impact depending on host country's requirements, missions and specifications of the expatriate and their family. In order to help the expatriates to better understand cultural differences, it is necessary to favor and organize contacts with other expatriates, follow-ups and acquisition of skills, meetings with local people, a short-term stay before expatriation (according to the country of expatriation), the presence of a mentor in the host country. Some countries require longer period for adaptation, therefore longer period and/or several short-term travels should be organized. Part of expatriation is therefore part of training.

Our study points the importance of support out, mainly when the expatriation occurs in a culturally different country; even more if the expatriation period is quite short (one to two years). Each organization should also precise the mission of the expatriation (content, means, resources in the host county) and its understanding by the expatriate and colleagues both in the home and 
host countries. Problems occur because of misunderstanding of the expatriate's situation from the home company's point of view. It is essential that the purpose but also the conditions and means of expatriation are well understood in the main offices as to help the expatriate wisely and to take advantage of this experience.

Local human resources have a great role to play (Schaaper, Amann, Jaussaud, Nakamura, Mizoguchi, 2013). They are responsible for implementing communication between the company, subsidiaries and the expatriates who work there. This means organizing the function of human resources locally in order to favor the support and coaching of expatriates. According to some expatriates, the company should also warn them that adaptation is not always that easy and that preparation is highly recommended in case of uncertainties during the work. It is also clear for most of the expatriates that they are not fully aware of the problems that may arise due to the fact that they are far away from their broader family that stayed in the home country.

It is as much the role of the human resources department to make sure the advantages and the mission of the expatriation are well defined as to make sure the expatriate and the company are aware of the difficulties they may encounter and the unpredictable aspect of an expatriation.

We purpose also to define a first expatriation as a training time for the following expatriations, especially if the following expatriation is in a context culturally different or if work conditions are different of these from the home countries. This first expatriation will have to be longer to impact the next expatriation and to enable the expatriate to prepare for cultural differences, acculturation and change in different context. After, the beginning of each expatriation will be training at the particular condition of expatriation but will be more eased and accelerated, as the expatriate already is trained in adapting and cultural differences but as to learn about the particularities of this expatriation.

As a conclusion, it is obvious the expatriation frame, purpose and means have to be clearly defined to ensure a successful and efficient experience. In addition to the awareness that the 
expatriate has about his own expatriation, coaching and support should be provide by the company as much as possible for a successful expatriation. A first expatriation could be organized by different period, in which the first one would be the combination of the discovery of their host country, their activities related to their mission and a complete coaching or mentoring. This implies that expatriates wouldn't be effective on the first hour of arrival but would increase their autonomy and adaptability as well as the benefits of the mission on the long term.

\section{References}

1. Aycan, Z. (1997). Expatriate adjustment as a multifaceted phenomenon: individual and organizational level predictors. The international journal of human resource management, 8(4), 434-456.

2. Baliga, G.M., \& Baker, J.C. (1985). Multinational corporate policies for expatriate managers : Selection, training, evaluation. Advanced management journal, 50(4), $31-38$.

3. Black J.S. (1990). The relationship of personal characteristics with the adjustment of Japanese expatriate managers. Management International Review, 30(2), 119-134.

4. Black J.S.\& Gregersen, H.B. (1991). Antecedents to cross-cultural adjustment for expatriates in Pacific Rim assignments”. Human Relations, 44 (5), 497-515.

5. Bonache, J.; Brewster, C., \& Suutari, V. (2001). Expatriation: a developing research agenda. Thunderbird International Business Review, 43(1), 3-20.

6. Briscoe, D.R., Schuler, R.S., \& Claus, L. (2009). International human resource management: Policies and practices for multinational enterprises. New-York: Routledge.

7. Church, A. (1982). Sojourner adjustment. Psychological Bulletin, 91 (3), 540-577. 
8. Gertsen M.C. (1990). Intercultural competence and expatriates. International journal of human resource management, 1(3), 341-362.

9. Guerrero, S., Cerdin, J.L. \& Roger, A. (2004). La gestion des carriers: enjeux et perspectives. Paris. Vuibert.

10. Harrison, J.K. (1994). Developing successful expatriate managers: a framework for the structural design and strategic alignment of cross-cultural training programs. Human resource planning, 17(3), 17-35.

11. McCaughey, D., \& Bruning, N.S. (2005). Enhancing opportunities for expatriate job satisfaction: HR strategies for foreign assignment success. Human resource planning, 28(4), 21-29.

12. Mendenhall, M.E., \& Oddou, G.R. (1986). Acculturation profiles of expatriate managers: implications for cross-cultural training programs. Columbia journal of world business, 21(4), 73-79.

13. Mendenhall, M.E., Oddou, G.R., \& Stahl, G.K. (2007). Readings and cases in international human resource management. New-York: Routledge.

14. Mérignac, O.\& Roger, A. (2005). L'impact du conjoint et de la famille sur l'adaptation des cadres expatriés. Revue de gestion des ressources humaines, 58, 2-13.

15. Miles, M.B. \& Huberman, A.M. (2003). Analyse des données qualitatives. Bruxelles. Paris : De Boeck.

16. Oddou, G.R. (1991). Managing your expatriates: What the successful firms do. Human resource planning, 14(4), 301-308. 
17. Perkins S.J., \& Shortland, S.M. (2006). Strategic international human resource management: Choices and consequences in multinational people management. London: MPG Books Ltd.

18. Quivy ,R.\& Van Campendoudt, L. (2011).

19. Romero, E.J. (2002). The effect of expatriate training on expatriate effectiveness. Journal of management research, 2(2), 73-78.

20. Schaaper, J., Amann, B., Jaussaud, J., Nakamura, H.\& Mizoguchi, S.(2013), Human resource management in Asian subsidiaries: comparaison of French and Japanese MNCs. The international Journal of Human Resource Management, 24(7), 1454-1470.

21. Scullion, H. (1994). Staffing policies and strategic control in British multinationals. International studies of management and organization, 24(3), 86-104.

22. Scullion, H., \& Collings, D.G. (2006). Global Staffing. New-York: Routledge.

23. Sekiou, L., Blondin, L., Fabi, B., Bayad, M., Peretti, J.-M., Alis, D. \& Chevalier, F. (2001). Gestion des ressources humaines. Montréal: 4L Inc.

24. Selmer, J. (2002). To train or not to train? European expatriate managers in China. International journal of cross-cultural management, 2(1), 37-51.

25. Selmer, J., Torbiörn, I., \& de Leon, C.T. (1998). Sequential cross-cultural training for expatriate business managers: pre-departure and post-arrival. The international journal of human resource management, 9(5), 831-840.

26. Tung, R.L. (1981). Selection and training of personnel for overseas assignments. Columbia journal of world business, 16(1), 68-78. 
27. Tung, R.L. (1987). Expatriate assignments: enhancing success and minimizing failure. Academy of management executive, 1 (2), 117-126.

28. Tung, R.L. (1998). American expatriates abroad from neophytes to cosmopolitans. Journal of world business, 16 (1), 68-78.

29. Vance, C.M., \& Paik, Y. (2010). Managing a global workforce: challenges and opportunities in international human resource management. New-York: M.E. Sharpe, Inc.

30. Van Campdendoudt, L. \& Quivy, R .(2011). Manuel de recherché en sciences sociales. Paris : Dunod.

31. Varner, I.I., \& Palmer, T.M. (2005). Role of cultural self-knowledge in successful expatriation. Singapore management review, 27(1), 1-25.

32. Vögel, A.J., \& van Vuuren, J.J. (2008). Preparation, support and training requirements of South African expatriates. South African journal business of management, 39(3), $33-40$.

33. Waxin, M.-F., \& Barmeyer, C. (2008). Gestion des ressources humaines internationales : problématiques, stratégies et pratiques. Pa ris : Liaisons.

34. Yin, R.K.. (2009). Case Study Research. London:Sage. 